\title{
Memorial da Terra. Tentaram nos enterrar, mas não sabiam que éramos sementes.
}

\author{
Hugo do Nascimento ${ }^{1}$
}

1 Artista, músico e arte-educador. Egresso do curso de Artes Visuais da Universidade Federal do Pará [2016] e pósgraduando no programa de Diversidade Sociocultural do Museu Paraense Emílio Goeldi [2020]. Nativo na Amazônia ou nômade pelo mundo, tem desenvolvido pesquisas nas encruzilhadas de uma arte política que busca pensar os modos de ver, de ocupar e significar os territórios de onde emerge. Museu Paraense Emílio Goeldi [PPGDS-MPEG]. E-mail: Hugartss@gmail.com. Lattes iD: http://lattes.cnpq.br/0442628823084070. Belém, Brasil. 
Memorial da Terra.

Tentaram nos enterrar, mas não sabiam que éramos sementes. 

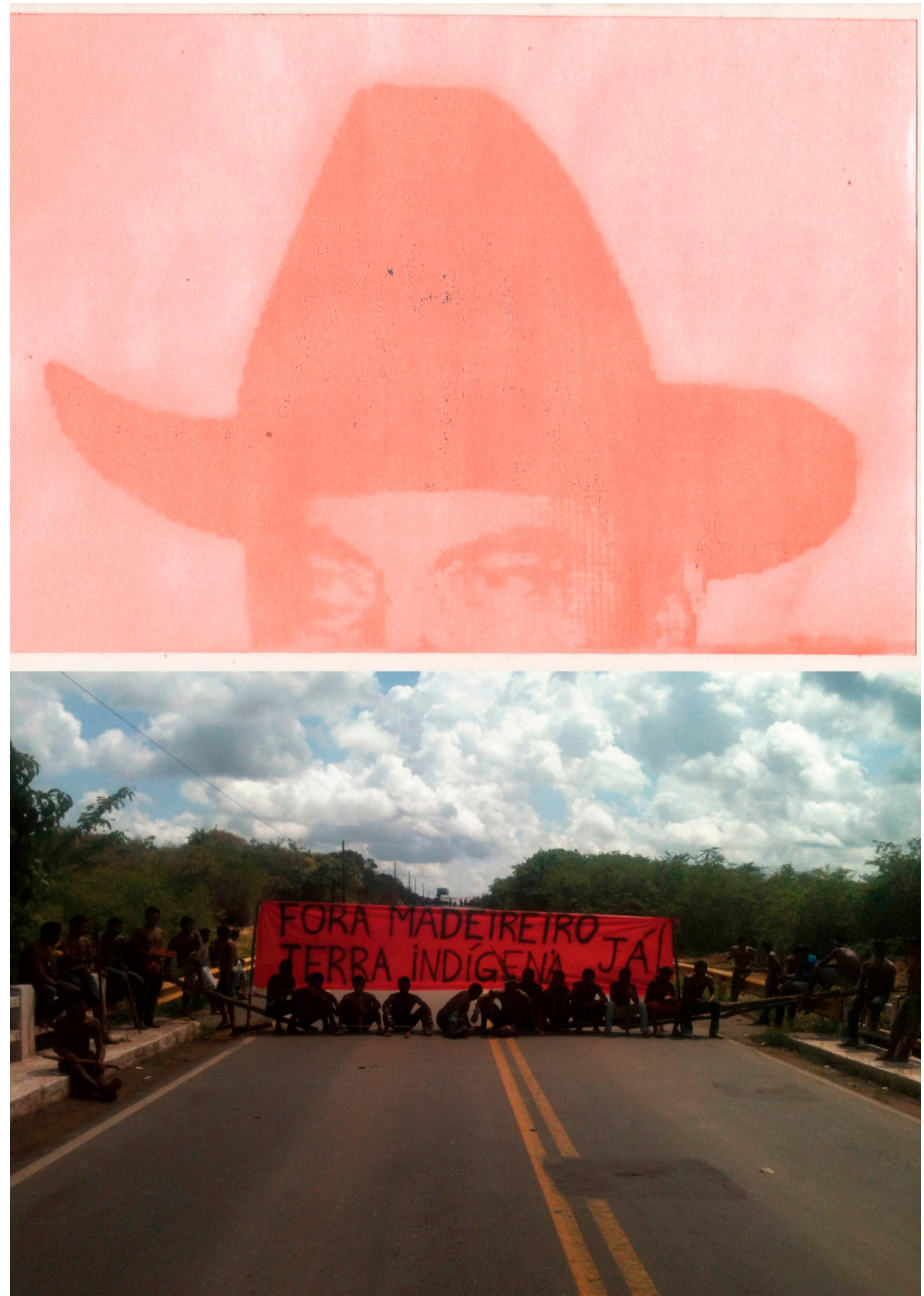

Quintino Lira [Urucum sobre papel, Fotocópia, 2020] + Ka `apor Protestam na BR-316 [Fotografia Digital, Zé Doca-MA, 2015] 


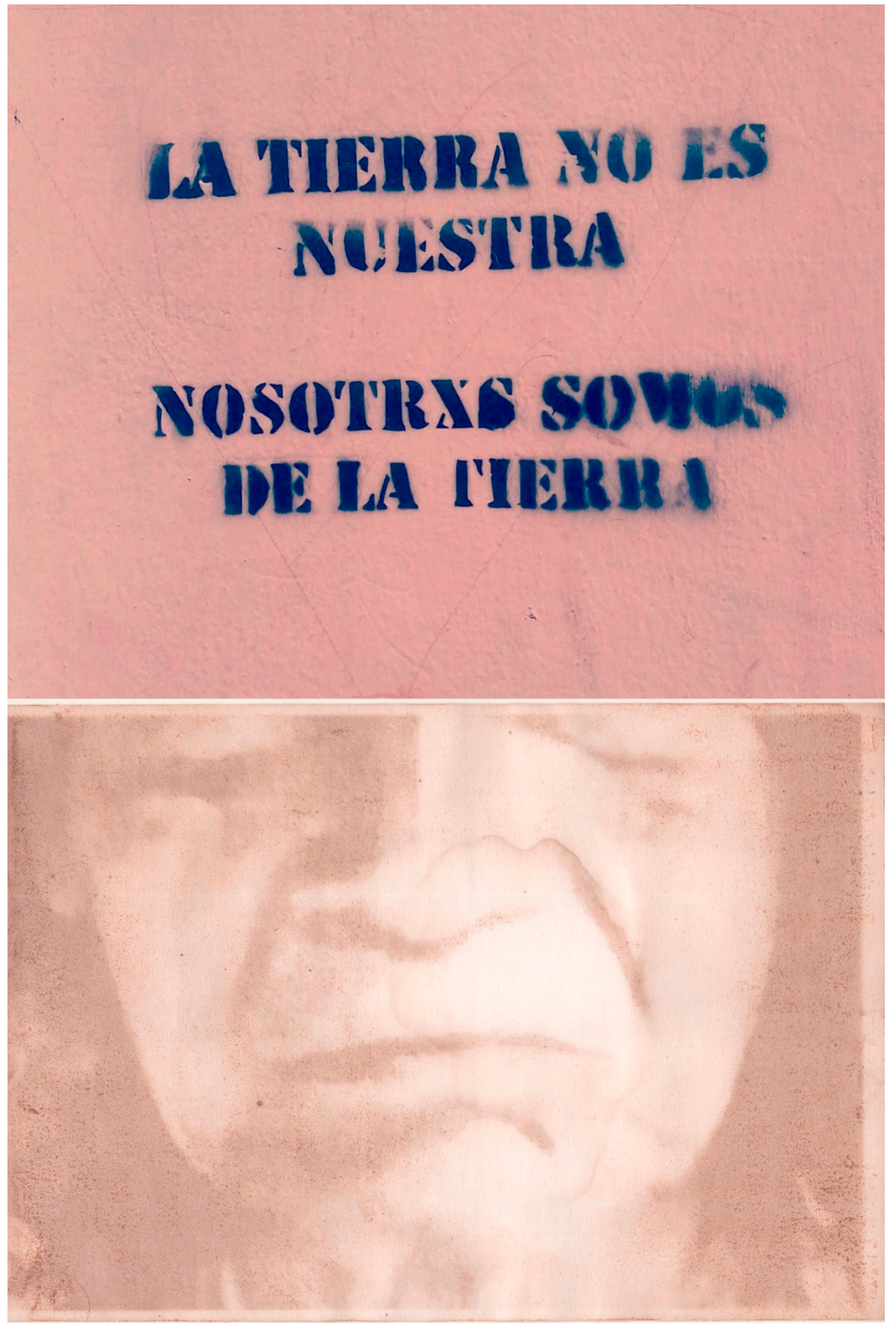

Stencil nos muros de Quito [Fotografia de Celular, Ecuador, 2019]

+ Emyra Waiãpi [Jenipapo sobre papel, Fotocópia, 2020] 

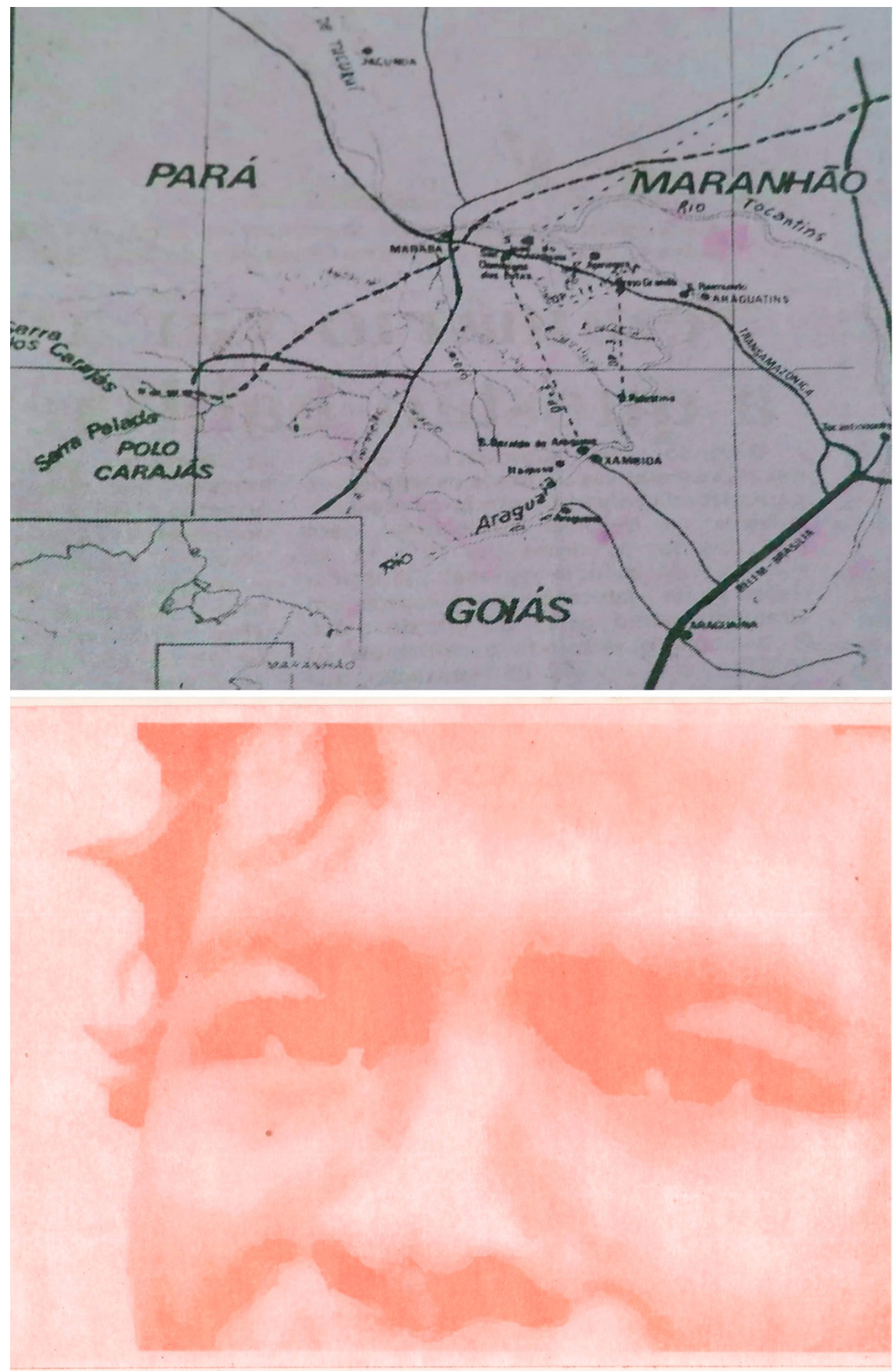

Mapa de Fronteira [Digitalizado dos arquivos da CPT-Belém, 2019]

+ Paulino Guajajara [Urucum sobre papel, Fotocópia, 2020] 

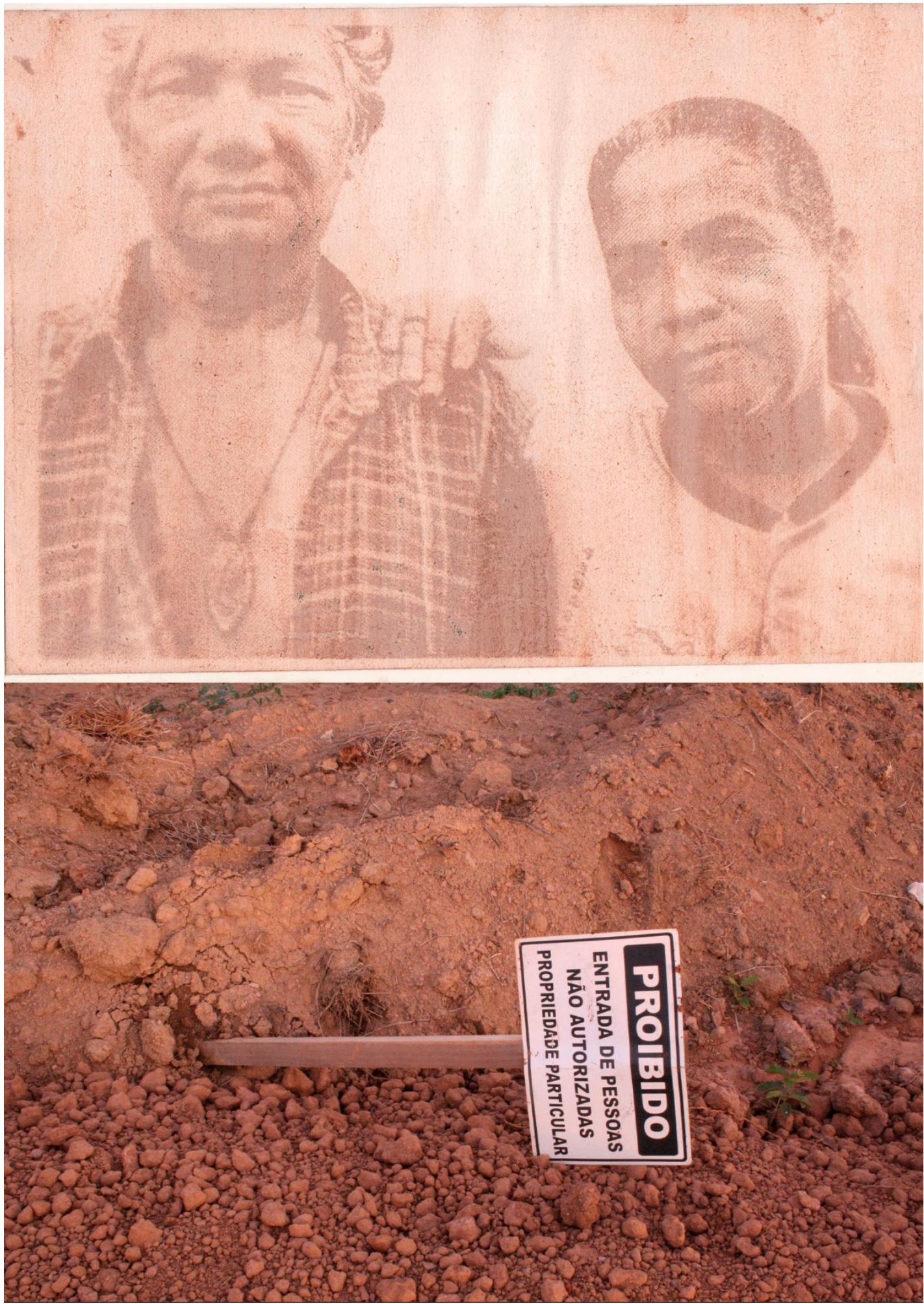

Zé Claudio e Maria [Jenipapo sobre papel, Fotocópia, 2020]

+ Propriedade Particular [Fotografia Digital, Canteiro de Obras da UHE Belo Monte, 2011] 
Memorial da Terra é um projeto de investigação permanente que propõe desde os lugares da arte, miradas críticas acerca das dinâmicas territoriais na Amazônia - os modelos de ocupação e exploração, as violências estruturais, os modos de representação, os processos de identificação, desvios e silenciamentos. Trabalho de inventariação sempre inacabado, pode assumir diferentes formas ao se tornar público. Em "Tentaram nos enterrar, mas não sabiam que éramos sementes", ao relacionar imagens documentais (produzidas ou coletadas durante percursos artivistas pela região) a fotografias orgânicas de vítimas de conflitos pela terra (copiadas por meio de emulsões fotossensíveis provenientes da natureza local), o que se busca é construir esse espaço narrativo no qual memórias dissidentes são lembradas e fortalecidas, e toda trajetória coletiva de luta dos povos tradicionais da Amazônia é homenageada. Esperança vive! Este trabalho é também dedicado a Arthur Leandro Maroja - Táta Kinamboji - mestre de toda uma geração de artistas combativos do Norte.

Hugo do Nascimento

Recebido em 18 de abril de 2020 e aceito em 19 de junho de 2020.

Este é um artigo publicado em acesso aberto sob uma licença Creative Commons $(\mathbf{c c})$ B Er 